\title{
Producing word of mouth - a matter of self-confidence? Investigating a dual effect of consumer self-confidence on WOM
}

\begin{abstract}
Several researchers emphasize the importance of consumer self-confidence in the production of word of mouth (WOM). However, most focus has been on consumer selfconfidence as a positive WOM predictor, and a possible negative relationship between consumer self-confidence and WOM remains largely unexplained. Here, we aimed to elucidate the possibility of both a positive and a negative effect of consumer self-confidence on WOM production, attributed to different dimensions of consumer self-confidence. Our results support this idea, demonstrating a positive effect of social consumer confidence on WOM and a negative effect of personal consumer confidence on WOM. Furthermore, we identify unique personality roots for each of the two dimensions of consumer self-confidence that provide explanations for their differential effects on WOM. In addition, this study shows that the dual effects of social and personal consumer confidence on WOM happen due to a suppression effect. Hence, we provide a statistical explanation that could be crucial in understanding the relationship between the multiple dimensions of consumer self-confidence and WOM. The findings have implications for the targeting of consumers for WOM marketing campaigns.
\end{abstract}

Keywords: word of mouth; consumer self-confidence; personality; suppression effect 


\section{Producing word of mouth - a matter of self-confidence? Investigating a dual effect of consumer self-confidence on WOM}

WOM involves the transmission of a consumer's informal opinion about products and brands derived from consumption experiences or advertising (Keller and Fay, 2012). This pervasive phenomenon occurs across most purchasing processes and is proven to exert considerable influence over consumer decisions (East et al., 2005). However, while it is clear that people give WOM frequently, and that such communication has important implications for consumer behavior, ambiguities still exist in our knowledge about the causes of WOM.

One such ambiguity relates to WOM as a behavior conducted by "the self-confident consumer.” This is a typical belief in the marketing literature (Bearden et al., 2001; Mazzarol et al., 2007), which is supported by research showing that consumer self-confidence is a precursor of market mavenism (Chelminski and Coulter, 2007; Clark et al., 2008). However, some researchers indicate that the picture of the self-confident consumer as an active WOM producer may be more complex. Specifically, Paridon et al. (2006) find that consumer selfconfidence in social outcomes (henceforth 'social consumer confidence') is positively related to WOM, while consumer self-confidence in personal outcomes (henceforth 'personal consumer confidence') has a weak, negative relationship with WOM. In other words, separate dimensions of consumer self-confidence might have opposite relationships with the production of WOM.

In light of the literature on the motives of WOM (Berger, 2014), the idea that consumer self-confidence also may have a negative effect on WOM seems plausible. For instance, research shows that consumers use WOM to cope with uncertainty and cognitive dissonance (Lindberg-Repo and Grönroos, 1999). Nonetheless, the negative relationship between consumer self-confidence and WOM is scarcely acknowledged in the WOM 
literature, and even Paridon et al. (2006) more or less ignore this finding when discussing their results. Several weaknesses and uncertainties associated with their results may explain why. Thus, there is no clear understanding of whether consumer self-confidence actually has both a positive and a negative effect on WOM and, if so, why this is the case. Considering the interest among marketers in identifying and targeting consumers with a higher tendency to disseminate WOM (Liu-Thompkins, 2012), elucidating the potentially opposing effects of the different dimensions of consumer self-confidence on WOM seems an important task.

This study takes on this task by testing a model linking social and personal consumer confidence with WOM production. Thus, this research provides a clearer assessment of WOM as a function of consumer self-confidence than previous investigations, which mix WOM production either with items that reflect receiving WOM (Paridon et al., 2006) or with items that reflect consumers' ability to influence others (Chelminski and Coulter, 2007; Clark et al., 2008).

In addition, this study aims to explain why different dimensions of consumer selfconfidence might have different effects on WOM by examining their nomological networks. Based on the notion that consumer traits such as consumer self-confidence are rooted in basic personality traits (Mowen et al., 2007; Steenkamp and Maydeu-Olivares, 2015), the current study includes extraversion and neuroticism in the research model. These two traits are chosen as they should be related to self-confidence (Cheng and Furnham, 2002), and thus could help illuminate the mechanisms underlying personal consumer confidence and social consumer confidence as predictors of WOM.

Finally, this study seeks a statistical explanation for the effects of personal and social consumer confidence on WOM, which may explain much of the ambiguity around the findings of Paridon et al. (2006). In their study, personal consumer confidence goes from a positive relationship with WOM in the correlation analysis to a negative relationship in the 
regression analysis. Thus, there might have been confusion regarding the 'true' effect of personal consumer confidence, which may explain why the researchers ignore its 'unexpected' negative effect on WOM in the regression analysis.

Our belief is that the shift from a positive effect in the correlation analysis to a negative effect when controlling for the other variables in the regression analysis may indicate that Paridon et al. (2006) encountered a suppression effect. A suppression effect refers to a situation wherein the predictive validity of an independent variable is improved by including another variable (or set of variables) in the regression equation (Conger, 1974). This can occur when the independent variables in the regression analysis correlate with each other and where one independent variable suppresses an outcome-irrelevant variation in another. This can potentially change a positive effect into a negative one, referred to as a crossover suppression effect (Paulhus et al., 2004). In those cases, the original valence of a variable is misleading, and its inclusion in a multiple regression analysis yields the 'genuine' effect of the variable. This study examines the possibility that this is the case for personal consumer confidence and proposes that social consumer confidence suppresses much of its outcomeirrelevant variance. If a suppression effect between social and personal consumer confidence on WOM can be demonstrated, this would be crucial in explaining the contradictory results regarding personal consumer confidence and WOM. To test the model of this research, a nationwide representative sample of 574 respondents is used, providing more generalizable results than previous studies (Paridon et al., 2006).

\section{Theoretical Framework}

\subsection{Word of Mouth}

Assessments of WOM production vary in their specificity. WOM is sometimes examined in relation to specific contexts, such as a company (Harrison-Walker, 2001) or a product/service 
(Berger and Schwartz, 2011), whereas at other times, it has been examined in connection with broader product categories (Gnambs and Batinic, 2012). At the most general level, researchers have defined WOM as a behavioural tendency to discuss various products and brands across product categories and consumption contexts (Chelminski and Coulter, 2007; Mowen et al., 2007). This research is interested in testing the premise that WOM is a behavioural outcome of consumer traits that, presumably, are relatively stable over time and across contexts (Steenkamp and Maydeu-Olivares, 2015). Thus, the measurement of WOM was approached as a general consumer tendency to produce product- and brand related communication that can be observed across categories and contexts.

While some studies also assess WOM in terms of its valence, this study is interested in how much WOM consumers produce, regardless of whether they give positive or negative WOM. By adopting this overall WOM production construct, we provide insights about the volume aspect of WOM. This aspect, reflecting how much WOM consumers produce, has a distinctive influence on consumers' decision-making process (Khare et al., 2011), and might be more influential in affecting consumer decisions than the valence aspect of WOM (Liu, 2006). Hence, studying WOM production as a distinct construct should be important in its own right.

\subsection{Conceptual framework}

The conceptual model of this research (see Figure 1) is inspired by personality and consumer trait theories proposing that traits reside in a structure in which more abstract, crosssituational traits influence narrower consumer traits which in turn influence behaviour (Mowen et al., 2007; Steenkamp and Aydey-Olivares, 2015). At the most abstract trait level, researchers commonly adopt traits within the Big Five framework (Costa and McCrae, 1992) that would be relevant to the purpose of the study (Matzler et al., 2011; Mooradian and Olver, 
1997; Sun and Wu, 2011). For instance, Mooradian and Olver (1997), who investigate emotions as predictors of post-purchase behaviour, include extraversion and neuroticism at the abstract trait level as they are probable predictors of emotions. The present study also includes these two traits at the abstract level, as previous research has indicated that these to some extent explain individuals' self-confidence (Cheng and Furnham, 2002).

Although the main purpose of including higher-order traits in the model is to examine the personality roots of personal and social consumer confidence, this research also studies whether extraversion and neuroticism could be indirectly influencing WOM. Such indirect effects, if revealed, could provide an understanding of how consumer self-confidence might act as a mediator in the personality-WOM relationship.

Figure 1 here

Social consumer confidence concerns the level of confidence consumers have in their ability to make purchase decisions that generate positive outcomes regarding the reactions of others (Bearden et al., 2001). This type of consumer self-confidence is expected to relate to a stronger tendency of giving WOM (Clark et al., 2008; Paridon et al., 2006). An explanation for a positive relationship between social consumer confidence and WOM may be related to individuals' desire for positive feedback and their fear of negative feedback from others. One of the central motives of WOM is self-enhancement (Alexandrov et al., 2013); consumers have the need to be positively evaluated by others such as being regarded as an intelligent shopper (Sundaram et al., 1998) or as an interesting person (Berger and Scwartz, 2011). People who are confident in obtaining positive reactions from others due to their consumer choices are presumably more strongly motivated to provide WOM. Conversely, consumers who score low on social consumer confidence would likely be more reluctant to provide WOM. Such consumers would be more insecure about reactions from others and would 
probably be affected by the fear of receiving negative evaluations and feedback (e.g. ridicule) in WOM discussions (MacIntyre et al., 1999). They might also believe they have nothing meaningful or interesting to contribute regarding product and brand experiences and therefore would be more anxious about engaging in WOM. Consequently, the following hypothesis is proposed:

H1: Social consumer confidence has a positive effect on WOM.

Personal consumer confidence concerns the confidence consumers have in their ability to make purchase decisions that are personally satisfying (Bearden et al., 2001). This type of consumer self-confidence is expected to have a negative effect on WOM (Paridon et al., 2006). An explanation for this effect may be related to consumers' use of WOM to cope with uncertainty in making the right purchase decisions. Consumers show a higher propensity to give WOM when they need advice or need to resolve a problem related to a purchase (Hennig-Thurau et al., 2004; Sundaram et al., 1998). In other words, to obtain the information they need, consumers talk about products or services themselves. In a similar vein, research shows consumers are more likely to give WOM when a purchase is associated with higher risk (Berger, 2014), indicating that WOM is prevalent when consumers experience uncertainty and lower confidence.

Consumers with a lower confidence related to making purchases would probably also make use of WOM to regulate their emotions. These consumers would be more disposed toward making purchase decisions that result in anxiety and cognitive dissonance (Keng and Liao, 2013). Providing WOM could help people cope with or alleviate such feelings by generating social support (Duhachek and Iacobucci, 2005), reducing cognitive dissonance (Lindberg-Repo and Grönroos, 1999) or by allowing people to vent (Sundaram et al., 1998). It 
could therefore be reasonably expected that an individual with lower personal consumer confidence would produce more WOM, thus the following hypothesis is proposed:

H2: Personal consumer confidence has a negative effect on WOM.

Extraversion is a personality trait relating to one's preference for social interaction (Costa and McCrae, 1992). Individuals who score high on scales measuring extraversion have a strong need for social stimulation. Some studies indicate that extraversion may be linked to higher self-confidence, particularly social self-confidence. For instance, there is a positive relationship between extraversion and a person's confidence in handling social interactions (Cheng and Furnham, 2002). It is also a predictor of a person's confidence in effectively communicating with others (MacIntyre et al., 1999). Therefore, extraversion would be expected to have a positive effect on social consumer confidence. Extraversion is also related to general self-confidence (Cheng and Furnham, 2002), and it could consequently be presumed to have a positive effect on personal consumer confidence. Accordingly, this study proposes a third hypothesis:

H3: Extraversion has a positive effect on a) social consumer confidence and b) personal consumer confidence.

Neuroticism, sometimes known as emotional instability (Sun and $\mathrm{Wu}, 2011$ ), refers to an individual's tendency to experience psychological distress and chronic negative emotions and to display related behavioural and cognitive characteristics (Costa and McCrae, 1992). Neurotic individuals can become easily frustrated and are more disposed toward being in a negative mood (David et al., 1997). Research also shows that neurotic individuals are more likely to have low self-esteem (Robins et al., 2001; Watson et al., 2002) and lower general self-confidence (Cheng and Furnham, 2002). Although no previous research has linked 
neuroticism to consumer self-confidence, it seems likely that neurotic individuals' low levels of general self-confidence would also translate into lower self-confidence in the consumer context. Hence, this study proposes the following hypothesis:

H4: Neuroticism has a negative effect on a) social consumer confidence, and b) personal consumer confidence.

As indicated previously, this research suspects a crossover suppression effect (Paulhus et al., 2004) between social and personal consumer confidence in predicting WOM. Such an effect may explain conflicting findings in previous research concerning consumer selfconfidence and WOM. For instance, when Paridon et al. (2006) investigated the independent effects of social and personal consumer confidence on WOM, both dimensions showed a positive relationship with WOM. However, when the interrelationships between consumer self-confidence dimensions are controlled in a regression analysis, the effect of personal consumer confidence on WOM reverses and becomes negative. Clark et al. (2008) found a similar reversal in the effect of personal consumer confidence on WOM when moving from a correlation analysis to a multiple regression analysis though the results were not significant. Yet, the findings of both Clark et al. (2008) and Paridon et al. (2006) are indicative of a crossover suppression effect between dimensions of consumer self-confidence as predictors of WOM. Based on this, the following hypothesis is proposed:

H5: There is a crossover suppression effect between social and personal consumer confidence in predicting WOM.

Although some researchers assume that the Big Five traits may have a direct effect on WOM (Mowen et al., 2007), limited support for this assumption have been found. A study by Goodey and East (2008) showed effects of agreeableness, neuroticism and openness on WOM 
when breaking down on gender, but no effects were found for the overall population. Some argue that the abstractedness of the Big Five traits make them poor predictors of concrete WOM behaviours (Gnambs and Batinic, 2012). They argue that such abstract traits may impact WOM through traits on subsequent trait levels. This study adopts the latter approach and assumes that the two dimensions of consumer self-confidence mediate the effects of extraversion and neuroticism.

H6: Social consumer confidence and personal consumer confidence mediate the effects of extraversion and neuroticism on WOM.

\section{Methods}

\subsection{Data Collection and Sampling}

To test these hypotheses, the authors conducted an online survey of members from a consumer panel. Respondents were invited to complete the survey by email, which was administered by a professional research company and presented as a survey of general consumer habits. A total of 600 responses were collected from a nationwide representative sample of Norwegian individuals ranging from 20 to 70 years old. Some respondents were removed from the data set due to missing responses or obvious response patterns in their questionnaires. The effective sample size obtained was 574. Demographically, the sample consisted of $52 \%$ women and $48 \%$ men, and the mean age was 39 years. The respondents were compensated with points that could be used to purchase gifts.

\subsection{Instruments}

All measures were based on the existing literature, but some were adapted for the purpose of the present study. Measures of extraversion and neuroticism were adopted from the short form of the Big Five Inventory (Donnellan et al., 2006; Lang et al., 2011), and each trait was operationalised with four items. Neuroticism was measured with reversed items (e.g. 'I rarely 
have mood swings'), but these were reversed again prior to analysis in order to provide a more logical presentation of the results. Social consumer confidence and personal consumer confidence were operationalised with four and five items respectively as developed by Bearden et al. (2001). WOM production was operationalised with six items primarily based on Mowen et al. (2007) and Lam et al. (2009). See table 1 for an overview of the specific measures.

\subsection{Analytical Procedure}

The model was tested by way of a two-step structural equation modelling (SEM) procedure in Amos 20.0. First, the authors performed a confirmatory factor analysis to evaluate the construct validity. Then, a structural analysis was conducted using a maximum likelihood estimation to test the relationships described in the model. The fit of the model was evaluated according to conventional criteria (Browne and Cudeck, 1992), based on the root mean square error of approximation (RMSEA) and the comparative fit index (CFI). The model fit is considered acceptable if the CFI exceeds 0.90 and if the RMSEA is below 0.08. It is considered a good fit if the CFI exceeds 0.95 and if the RMSEA is below 0.05 .

Table 1 here

\section{Results}

\subsection{Reliability and Validity of the Measures}

The composite reliability (CR) and average variance extracted (AVE) were calculated to estimate each construct's internal consistency. The reliability analysis showed that the reliability of neuroticism was greatly improved by removing one of the construct's four items. After removing 'Remain calm in tense situations' from neuroticism, the authors obtained satisfactory reliabilities for all the latent constructs $(\alpha>0.70)$ (see Table 1). Moreover, for all 
the constructs, the average variances explained by the latent factors exceeded the commonly recommended threshold of 0.50 (Fornell and Larcker, 1981). Hence, the items operationalised the constructs adequately. The fit indices showed that the fit of the data with the overall model was acceptable $(\chi 2(197)=509, \mathrm{CFI}=0.95, \mathrm{RMSEA}=0.053)$.

Thereafter, this study assessed discriminant validity using a procedure suggested by Fornell and Larcker (1981). Their descriptive approach compared the squared correlation between two factors to the average indicator variances explained by the latent factor. If the AVE values were higher than the squared correlation, then discriminant validity was supported. This condition was met by all five constructs (see Table 1 and 2).

Table 2 here

\subsection{Testing the Hypotheses}

The results of the model revealed acceptable fit statistics $(\chi 2(200)=629, \mathrm{CFI}=0.94$, RMSEA $=0.061$ ). The model accounted for $36 \%$ of the variance in WOM. All the results of the analysis are presented in Table 3, which shows the path coefficients for the hypothesized effects with their corresponding significance levels. The results show that social consumer confidence has a positive effect on WOM and personal consumer confidence has a negative effect on WOM, supporting H1 and H2. For the abstract level traits, extraversion has a positive effect on social consumer confidence and personal consumer confidence, supporting $\mathrm{H} 3 \mathrm{a}$ and $\mathrm{H} 3 \mathrm{~b}$. Neuroticism has a significant negative effect on personal consumer confidence, which supports H4b. However, neuroticism did not show a significant relationship with social consumer confidence; thus, $\mathrm{H} 4 \mathrm{a}$ is not supported. In other words, social consumer confidence is predicted by only extraversion, while personal consumer confidence is predicted by both neuroticism and extraversion. 
Table 3 here

\subsection{Testing for Crossover Suppression Effect}

Consistent with the findings of Paridon et al. (2006), the correlation analysis in this study has revealed a positive correlation between personal consumer confidence and WOM. In light of the negative effect of personal consumer confidence on WOM in the SEM analysis, there was initial evidence that the personal consumer confidence predictor might be the object of a crossover suppression effect (Paulhus et al., 2004). To test this statistically, a necessary first step was to examine whether social consumer confidence was the suppression variable or whether one of the other two variables was re-directing the effect of personal consumer confidence on WOM. Although social consumer confidence seemed like the most likely suppression variable based on previous research, our SEM model included four predictors that all correlated with each other. Hence, we could not immediately rule out suppression variables other than social consumer confidence.

Consequently, personal consumer confidence was tested as a WOM predictor in combinations with each of the other three traits in order to determine which ones had specifically affected the personal consumer confidence estimate. This exercise showed that the effect of personal consumer confidence on WOM was positive when predicting WOM alone or together with extraversion and neuroticism but became negative when social consumer confidence entered the model. Hence, social consumer confidence seemed to act as the suppressor variable, changing the effect of personal consumer confidence on WOM.

Further analysis was conducted to test the suppression effect by constructing separate SEM models for the relationships between each of the consumer self-confidence variables and WOM. When the path analysis included only personal consumer confidence and WOM, it showed a positive relationship between these variables $(\beta=0.15, p<0.01)$. Similarly, the 
relationship between social consumer confidence and WOM tendency was positive $(\beta=0.54$, $p<0.01)$. However, when testing a model with both predictors, the relationship between personal consumer confidence and WOM became significantly negative $(\beta=-0.22, p<0.01)$, while the relationship between social consumer confidence and WOM became more positive $(\beta=0.66, p<0.01)$. These findings suggest that there might be a crossover suppression effect between social and personal consumer confidence in predicting WOM. In addition, the findings also indicate a mutual suppression effect (Tzelgov and Henik, 1991) where not only social consumer confidence acts as a suppressor variable in the relationship between personal consumer confidence and WOM, but personal consumer confidence also suppresses some of the variance in social consumer confidence improving the effect of the latter on WOM.

To evaluate the significance of these suppression effects, we conducted a mediation analysis using the bootstrapping method (Shrout and Bolger, 2002). Suppression effects are observed when the direct effect is opposite in sign to the indirect effect. As Table 4 shows, the total effect (i.e. not controlling for social consumer confidence) of personal consumer confidence on WOM was positive and statistically significant. However, the direct effect (i.e. controlling for social consumer confidence) of personal consumer confidence on WOM was negative and statistically significant. Most importantly, the indirect effect of personal consumer confidence, through social consumer confidence, was positive and statistically significant $(\beta=0.38, p<0.01)$. Furthermore, the total effect (i.e. not controlling for personal consumer confidence) and the direct effect (i.e. controlling for personal consumer confidence) of social consumer confidence on WOM were both positively and statistically significant. The indirect effect of social consumer confidence, through personal consumer confidence, was negative and statistically significant $(\beta=-0.13, p<0.01)$. These findings support H5 concerning a crossover suppression effect between social and personal consumer confidence in predicting WOM. In addition, it is proved that personal consumer confidence improves the 
effect of social consumer confidence on WOM, providing evidence of a mutual suppression effect.

Table 4 here

\subsection{Testing for Mediation Effects}

This study has also examined the proposed mediation effect of consumer self-confidence using the bootstrapping method. The results of this test (see Table 5) revealed that extraversion has a positive indirect effect on WOM through social consumer confidence $(\beta=$ $0.24, p<0.01)$ and a negative indirect effect on WOM through personal consumer confidence $(\beta=-0.04, p<0.01)$. Additionally, the results show that neuroticism has a positive indirect effect on WOM through personal consumer confidence $(\beta=0.03, p<0.01)$ but no indirect effect through social consumer confidence.

The second step in testing for mediation was to examine whether the indirect effects explain a direct effect that was initially present when the mediators were not considered. Therefore, the direct effects of extraversion and neuroticism on WOM were determined without consideration of the mediator. As Table 5 shows, extraversion $(\beta=0.33, p<0.01)$ and neuroticism $(\beta=0.11, p<0.05)$ had significant direct effects on WOM.

The results of the mediation test show that the relationship between extraversion and WOM is mediated by both personal and social consumer confidence, while the relationship between neuroticism on WOM is mediated by personal consumer confidence. Hence, we provide partial support for H6. However, the mediating role of personal consumer confidence between both extraversion and WOM and between neuroticism and WOM should be interpreted with caution due to the very low indirect effect sizes. 


\section{Discussion}

The results of our structural model confirm that social consumer confidence is a positive predictor of WOM production and that personal consumer confidence is a negative predictor of WOM production (Paridon et al., 2006). In addition, social and personal consumer confidence are shown to have roots in different personality traits. Social consumer confidence is rooted in extraversion while personal consumer confidence is rooted in both extraversion and neuroticism. Lastly, the assumption that the negative effect of personal consumer confidence on WOM reveals itself by the virtue of a suppression effect is verified.

This study contributes to the WOM literature comprising antecedents of WOM by demonstrating that WOM production is a function of both higher and lower consumer selfconfidence. While previous research gives some indication of this dual effect of consumer self-confidence (Paridon et al., 2006), the evidence is associated with much ambiguity, and the effect has until now remained largely unexplained in the literature. This study tests a model of consumer and personality trait predictors of WOM on a representative sample of 574 respondents, which provides both a psychological and a statistical explanation for the contradictory effects of social and personal consumer confidence on WOM. However, the negative effect of personal consumer confidence should be interpreted with some caution as findings from the bivariate correlation analysis shows that this effect could be positive. Yet, the negative effect found in the multivariate path analysis is compatible with previous research on motivations for giving WOM (Berger, 2014), and is demonstrated within reasonable limits when one considers the evidence of a suppression situation between social and personal consumer confidence. On this basis, this research suggests a negative effect of personal consumer confidence on WOM production is plausible.

Psychologically speaking, this study provides an understanding of the relationship between consumer self-confidence and WOM by identifying unique personality roots for each 
of the two dimensions of consumer self-confidence. First, the results reveal that social consumer confidence, which has a positive effect on WOM (Clark et al., 2008; Paridon et al., 2006), is rooted in the trait of extraversion. Thus, the stronger WOM evident amongst those consumers with greater social consumer confidence can be attributed to their more extraverted personalities at an abstract trait level. This finding extends previous research (Cheng and Furnham, 2002), showing that extraverts' higher social confidence is also transferable to the consumer context. In addition, the mediation analysis shows that social consumer confidence mediates the relationship between extraversion and WOM. Hence, a linkage is built from a central human trait to WOM, via a previously established trait predictor of WOM at the consumer level. This provides a more coherent theory of WOM as rooted in a hierarchy of consumer and personality traits (Mowen et al., 2007).

In addition, the results demonstrate that personal consumer confidence, which has a negative effect on WOM (Paridon et al., 2006), is negatively influenced by neuroticism and positively influenced by extraversion. Hence, the higher disposition to give WOM evident among consumers with lower levels of personal consumer confidence can be traced to their more neurotic and introverted personalities at an abstract trait level. Especially relevant in developing the understanding of personal consumer confidence as a negative predictor of WOM is its relationship with neuroticism. As social consumer confidence is not rooted in this personality trait, neuroticism seems to explain a characteristic of personal consumer confidence different from social consumer confidence, which again could explain their opposite effects on WOM.

This study suggests, for instance, that consumers with lower levels of personal confidence are more likely to be active WOM transmitters due to their need to cope with insecurities and negative emotions as consumers. As we show that these consumers are also more likely to have a neurotic personality, and thus more predisposed toward experiencing 
distress and negative emotions (Costa and McCrae, 1992), we demonstrate the feasibility of this theory. The positive indirect effect of neuroticism on WOM via personal consumer confidence provides additonal evidence for this theory. Although the effect is weak, it suggests that neuroticism may cause WOM by weakening personal consumer confidence.

Statistically speaking, this study resolves much of the ambiguity concerning the negative relationship between personal consumer confidence and WOM by showing there is a suppression effect among the two consumer self-confidence dimensions and WOM. The positive effect of personal consumer confidence on WOM according to the correlation analysis (Paridon et al., 2006), turns into a negative effect when personal consumer confidence is inserted into the structural model together with social consumer confidence. In other words, we reveal a possible crossover suppression effect (Paulhus et al., 2004) where social consumer confidence, by the virtue of correlating with personal consumer confidence, forces a redirection in the validity of the latter as a WOM predictor. Before controlling for the correlation between social and personal consumer confidence, the overlap of the predictors was potentially forcing the validities to converge more than was warranted by their independent effects. Thus, the positive relationship between personal consumer confidence and WOM in the correlation analysis might be illusory. Joint inclusion in a regression equation controlled for the overlap between the two dimensions of consumer self-confidence, yielding the 'genuine' negative effect of personal consumer confidence on WOM. Thus, the personal and social dimensions of consumer confidence might be less similar than they appear, given their high positive correlation.

Finally, it is worth noting the different strengths of the links between the dimensions of consumer self-confidence and WOM. The results have indicated that the link between social consumer confidence and WOM is stronger than the link between personal consumer confidence and WOM. This finding is consistent with the findings of Paridon et al., (2006). 
Furthermore, an examination of the strengths of the indirect effects in the mediation analysis suggests that the causal path from neuroticism, via personal consumer confidence, is less predictive of WOM than the path from extraversion via social consumer confidence. Given that negative emotions are suggested as an underlying premise for the former path, the results are consistent with studies showing that people are more willing to provide WOM based on positive rather than negative experiences (East et al. 2007).

\subsection{Managerial Implications}

In today's interactive marketing environment, knowing who is more likely to provide WOM could be critical for developing successful WOM strategies. Previous research examines this issue through the perspective of market mavens or through opinion leadership constructs (Gnambs and Batinic, 2012; Mowen et al., 2007) which include items that reflect consumers' ability to influence others along with items measuring WOM production. However, research suggests that the power of WOM lies as much in its ability to spread information as in its ability to persuade others (Liu, 2006). Thus, the current research is important for marketers, as it identifies consumer trait predictors of WOM reflecting consumers' WOM production tendencies only.

Particularly, the personality-based path to WOM including extraversion and social consumer confidence, which was the most powerful in this study, could have important implications for marketers. By being concerned with the social outcomes of their choices, extraverted and socially confident consumers would presumably share more positive than negative WOM about a brand or a product (Wien and Olsen, 2014). By identifying consumers with these traits (for example, through online questionnaires), companies may be able to establish contact with attractive 'seeds' for use in their WOM campaigns. 
Although social consumer confidence seems to be the stronger predictor of WOM, marketers should not ignore those consumers showing lower levels of personal consumer confidence in their management of WOM. These consumers would presumably talk to cope with cognitive dissonance, or in order to obtain advice or social support (Berger, 2014). Thus, these consumers would typically be the type that companies should be aware of in the implementation of customer support systems (Canhoto and Clark, 2013).

\subsection{Limitations and Further Research}

The findings of this study should be interpreted in light of its limitations. Given the unreliability of suppression effects (Paulhus et al., 2004), caution is required until the results of the present study can be replicated. Furthermore, there are some unanswered questions regarding the psychological explanation for the suppression effect identified in this study. For instance, what is the overlapping factor between personal and social consumer confidence that pushes them apart in the multivariate analysis and causes their diverging effects on WOM? More research is thus needed to provide an answer to why there is a suppression effect in the relationships between personal consumer confidence, social consumer confidence and WOM production.

The current study focuses on the activity aspect of WOM. Future research could extend to investigating consumer and personality trait predictors of other aspects of WOM, such as valence (Harrison-Walker, 2001) and content (Nguyen and Romaniuk, 2014). Research shows, for example, that different motives may underlie the production of positive versus negative WOM (Alexandrov et al., 2013; Sundaram et al., 1998). Likewise, certain personality traits may be more strongly associated with positive versus negative WOM. It could be expected, for instance, that neuroticism, which describes rather negative and pessimistic individuals, would have a stronger relationship with negative WOM than with 
positive WOM. Another possibility is that consumers with a high self-confidence would have a stronger propensity of expressing personal opinions as part of their WOM communication. Thus, a potential avenue for future research could be to study consumer and personality traits associated with WOM of different valence and content.

Another suggestion for future studies would be to explore additional personality traits that could be relevant to WOM. For instance, openness to experience and conscientiousness have been identified as predictors of opinion leadership (Gnambs and Batinic, 2012). It would be interesting, therefore, to investigate how these traits relate to WOM. In addition, future studies could test other consumer traits which could act as mediators in models with personality traits as predictors of WOM. The existing literature has identified, for instance, fashion innovativeness, shopping enjoyment, and value consciousness as trait predictors of market mavenism at the consumer trait level (Mowen et al., 2007). Investigations of these traits as WOM predictors, which also include their higher-level antecedents, would provide a more refined understanding of the causal links between personality and WOM.

Conducting a cross-sectional survey could be viewed as a final limitation of the study, which made it difficult to establish the direction of causality. The hypothesized and tested relationships were grounded in the existing literature. Future longitudinal or experimental studies should be conducted in order to test the strength of this study's causal model. 


\section{References}

Alexandrov A., Lilly B., Babakus E., 2013. The effects of social- and self-motives on the intentions to share positive and negative word of mouth. Journal of the Academy of Marketing Science 41 (5), 531-546.

Bearden W.O., Hardesty D.M., Rose R.L., 2001. Consumer self-confidence: Refinements in conceptualization and measurement. Journal of Consumer Research 28 (1), 121-134.

Berger, J., Schwartz, E.M., 2011. What drives immediate and ongoing word of mouth? Journal of Marketing Research 48 (5). 869-880.

Berger, J., 2014. Word of mouth and interpersonal communication: A review and directions for future research. Journal of Consumer Psychology 24 (4), 586-607.

Browne M.W., Cudeck R., 1992. Alternative ways of assessing model fit. Sociological Methods and Research 21 (2), 230-258.

Canhoto, A.I., Clark, M., 2013. Customer service 140 characters at a time: The users' perspective. Journal of Marketing Management 29 (5-6), 522-544.

Chelminski P., Coulter R.A., 2007. On market mavens and consumer self-confidence: A cross-cultural study. Psychology and Marketing 24 (1), 69-91.

Cheng H., Furnham A., 2002. Personality, peer relations, and self-confidence as predictors of happiness and loneliness. Journal of Adolescence 25 (3), 327-339.

Clark R.A., Goldsmith R.E., Goldsmith E.B., 2008. Market mavenism and consumer selfconfidence. Journal of Consumer Behaviour 7 (3), 239-248.

Conger, A.J., 1974. A revised definition of suppressor variables: A guide to their identification and interpretation. Educational and Psychological Measurement 34 (1), $35-46$.

Costa P.T., McCrae R.R., 1992. Normal personality assessment in clinical practice: The NEO Personality Inventory. Psychological Assessment 4 (1), 5-13.

David J.P., Green P.J., Martin R., Suls J., 1997. Differential roles of neuroticism, extraversion, and event desirability for mood in daily life: an integrative model of topdown and bottom-up influences. Journal of Personality and Social Psychology 73 (1), 149-59.

Donnellan M.B., Oswald F.L., Baird B.M., Lucas R.E., 2006. The mini-IPIP scales: tiny-yeteffective measures of the Big Five factors of personality. Psychological assessment 18 (2), 192-203.

Duhachek, A, Iacobucci, D. 2005. Consumer personality and coping: Testing rival theories of process. Journal of Consumer Psychology 15 (1), 52-63. 
East, R., Hammond, K., Lomax, W., Robinson, H., 2005. What is the effect of a recommendation? The Marketing Review, 5 (2), 145-157.

East, R., Hammond, K., Wright, M., 2007. The relative incidence of positive and negative word of mouth: A multi-category study. International Journal of Research in Marketing, 24 (2), 175-184.

Fornell C., Larcker D.F., 1981. Evaluating structural equation models with unobservable variables and measurement error. Journal of Marketing Research 18 (1), 39-50.

Gnambs T., Batinic B., 2012. A personality-competence model of opinion leadership. Psychology and Marketing 29 (8), 606-621.

Godes, D., Mayzlin, D., 2004. Using online conversations to study word-of-mouth communication. Marketing science 23 (4), 545-560.

Goodey, C., East, R., 2008. Testing the market maven concept. Journal of Marketing Management 24 (3-4), 265-282.

Harrison-Walker L.J., 2001. The measurement of word-of-mouth communication and an investigation of service quality and customer commitment as potential antecedents. Journal of Service Research 4 (1), 60-75.

Hennig-Thurau T., Gwinner K.P., Walsh G., Gremler D.D., 2004. Electronic word-of-mouth via consumer-opinion platforms: What motivates consumers to articulate themselves on the Internet? Journal of Interactive Marketing 18 (1), 38-52.

Keng, C.-J., Liao, T.-H., 2013. Self-confidence, anxiety, and post-purchase dissonance: a panel study. Journal of Applied Social Psychology 43 (8), 1636-1647

Khare, A., Labrecque, L.I., Asare, A.K., 2011. The assimilative and contrastive effects of word-of-mouth volume: An experimental examination of online consumer ratings. Journal of Retailing 87 (1), 111-126.

Lam D., Lee A., Mizerski R., 2009. The effects of cultural values in word-of-mouth communication. Journal of International Marketing 17 (3), 55-70.

Lang F.R., John D., Lüdtke O., Schupp J., Wagner G.G., 2011. Short assessment of the Big Five: robust across survey methods except telephone interviewing. Behavior research methods 43 (2), 548-67.

Lindberg-Repo, K., Grönroos, C., 1999. Word-of-mouth referrals in the domain of relationship marketing. Australasian Marketing Journal, 7 (1), 109-117.

Liu Y., 2006. Word of mouth for movies: Its dynamics and impact on box office revenue. Journal of Marketing 70 (3), 74-89.

Liu-Thompkins Y., 2012. Seeding viral content: The role of message and network factors. Journal of Advertising Research 52 (4), 465-478. 
MacIntyre P.D., Babin P.A., Clement R., 1999. Willingness to communicate: Antecedents \& consequences. Communication Quarterly 47 (2), 215-229.

Mazzarol, T., Sweeney, J.C., Soutar, G.N., 2007. Conceptualizing word-of-mouth activity, triggers and conditions: an exploratory study. European Journal of Marketing, 41 (11/12), 1475-1494.

Mooradian T.A., Olver J.M., 1997. "I can't get no satisfaction:” The impact of personality and emotion on postpurchase processes. Psychology and Marketing 14 (4): 379-393.

Mowen J.C., Park S., Zablah A., 2007. Toward a theory of motivation and personality with application to word-of-mouth communications. Journal of Business Research 60 (6), 590-596.

Nguyen, C., Romaniuk, J., 2014. Pass it on: A framework for classifying the content of word of mouth. Australasian Marketing Journal, 22 (2), 117-124.

Paridon T.J., Carraher S., Carraher S.C., 2006. The income effect in personal shopping value, consumer self-confidence, and information sharing (word of mouth communication) research. Academy of Marketing Studies Journal 10 (2), 107-124.

Paulhus, D.L., Robins, R.W., Trzesniewski, K.H., Tracy, J.L., 2004. Two replicable suppressor situations in personality research. Multivariate Behavioral Research 39 (2), 303-328.

Robins R.W., Tracy J.L., Trzesniewski K., Potter .J, Gosling S.D., 2001. Personality correlates of self-esteem. Journal of Research in Personality 35 (4), 463-482.

Shrout, P.E., Bolger, N., 2002. Mediation in experimental and nonexperimental studies: new procedures and recommendations. Psychological methods 7 (4), 422-445.

Steenkamp, J.B.E., Maydeu-Olivares, A., 2015. Stability and Change in Consumer Traits: Evidence from a 12-Year Longitudinal Study, 2002-2013. Journal of Marketing Research 52 (3), 287-308.

Sun T., Wu G. 2011., Trait predictors of online impulsive buying tendency: A hierarchical approach. The Journal of Marketing Theory and Practice 19 (3), 337-346.

Sundaram D.S., Mitra K., Webster C., 1998. Word-of-mouth communications: A motivational analysis. In Alba J.W., Hutchinson J.W. (eds). Advances in Consumer Research, Vol. 25. Association for Consumer Research: Provo, UT; 527-531.

Tzelgov, J., Henik, A., 1991. Suppression situations in psychological research: Definitions, implications, and applications. Psychological Bulletin 109 (3), 524-536.

Watson D., Suls J., Haig J., 2002. Global self-esteem in relation to structural models of personality and affectivity. Journal of Personality and Social Psychology 83 (1), 185197. 
Wien, A.H., Olsen, S.O., 2014. Understanding the relationship between individualism and word of mouth: A self-enhancement explanation. Psychology \& Marketing 31 (6), 416425. 
Figure 1

Research model

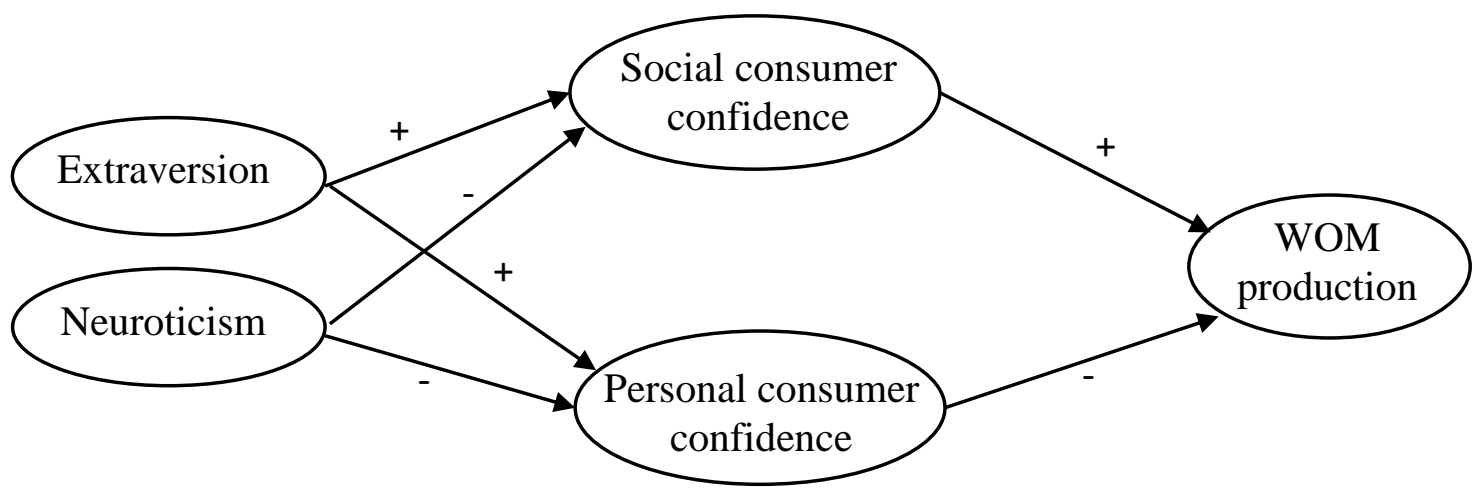




\section{Table 1}

Confirmatory factor analysis and measurement properties of the scales

Standardized Composite Variance

factor

reliability extracted

loadings

WOM production

$0.93 \quad 0.68$

1. I like introducing new brands and products to my friends and family

2. I like to talk to others about my product and brand experiences

3. I share information about new brands and products with people other than my close friends and family

4. I often tell others about new products and brands

5. I usually spend a lot of time sharing my knowledge about products and brands

6. I share brand and product information with others in various social occasions

1. I am the life of the party

2. I am very talkative 0.70

3. I talk to a lot of different people at parties

4. I am outgoing and sociable

Neuroticism

$0.74 \quad 0.50$

1. I rarely have mood swings (reversed) 0.79

2. I am not easily upset (reversed) 0.56 
3. I seldom feel blue (reversed)

Personal consumer confidence

1. I never have doubts about the purchase decisions that I make

2. I am always sure of what to buy

3. I never wonder if I've made the right purchase selection

4. I always feel I manage to buy the right thing for me

5. I am always satisfied with the things that I buy

Social consumer confidence

1. My friends are impressed with my ability to make satisfying purchases

2. I impress people with the purchases that I make

3. I have the ability to give good presents

4. I get compliments from others on my purchase decisions 0.79

0.86 0.55

0.78

0.70

0.86 0.61 
Table 2

Correlation matrix

\begin{tabular}{|c|c|c|c|c|c|}
\hline & 1 & 2 & 3 & 4 & 5 \\
\hline 1. WOM & - & & & & \\
\hline 2. Extraversion & $0.30 * *$ & - & & & \\
\hline 3. Neuroticism & -0.04 & $0.24 * *$ & - & & \\
\hline 4. Personal consumer confidence & $0.15 * *$ & $0.32 * *$ & $0.29 * *$ & - & \\
\hline 5. Social consumer confidence & $0.54 * *$ & $0.44 * *$ & $0.10 *$ & $0.56 * *$ & - \\
\hline M & 3.8 & 4.1 & 4.2 & 4.1 & 4.1 \\
\hline SD & 1.4 & 1.2 & 1.3 & 1.1 & 1.2 \\
\hline
\end{tabular}


Table 3

Test of structural model and research hypotheses

$\beta \quad$ Hypotheses

\section{Hypothesized effects}

$\begin{array}{lll}\text { Social consumer confidence -> WOM } & 0.61^{* *} & \text { H1 - supported } \\ \text { Personal consumer confidence -> WOM } & -0.16^{* *} & \text { H2 - supported } \\ \text { Extraversion -> Social consumer confidence } & 0.47^{* *} & \text { H3a - supported } \\ \text { Extraversion -> Personal consumer confidence } & 0.31^{* *} & \text { H3b - supported } \\ \text { Neuroticism -> Social consumer confidence } & -0.02 & \text { H4a - no support } \\ \text { Neuroticism -> Personal consumer confidence } & -0.22^{* *} & \text { H4b - supported }\end{array}$

${ }^{*} p<0.05: * * p<0.01 . \mathrm{R}^{2}$ for WOM: 0.36 
Table 4

Test for suppression effects

\begin{tabular}{lcc}
\hline Standardized direct effects & $\beta$ alone & $\begin{array}{c}\beta \text { with both } \\
\text { predictors }\end{array}$ \\
\hline Social confidence -> WOM & $0.55^{* *}$ & $0.66^{* *}$ \\
Personal confidence -> WOM & $0.15^{* *}$ & $-0.22^{* *}$ \\
Standardized indirect effects & $\beta$ \\
Social confidence -> Personal confidence -> WOM & \multicolumn{2}{c}{$-0.13^{* *}$} \\
Personal confidence -> Social confidence -> WOM & $0.38^{* *}$ \\
\hline$* p<0.05: * * p<0.01$ & &
\end{tabular}


Table 5

Test for mediation

\begin{tabular}{lc}
\hline Standardized direct effects without mediator & $\beta$ \\
\hline Extraversion -> WOM & $0.33^{* *}$ \\
Neuroticism -> WOM & $0.11^{*}$ \\
Standardized indirect effects & $\beta$ \\
Extraversion -> Social confidence -> WOM & $0.24^{* *}$ \\
Extraversion -> Personal confidence -> WOM & $-0.04^{* *}$ \\
Neuroticism -> Social confidence -> WOM & 0.008 \\
Neuroticism -> Personal confidence -> WOM & $0.03^{* *}$ \\
\hline$* p<0.05: * * p<0.01$ &
\end{tabular}

